\title{
LA ANALOGÍA SOCIOBIOLÓGICA DEL DESARROLLO DE LA CIENCIA, LA EPISTEMOLOGÍA EVOLUCIONISTA DE DAVID HULL
}

\author{
Rosaura Ruiz G. \\ Laboratorio de Historia de la Biología y Evolución, Facultad de Ciencias, UNAM. México, D.F. \\ Francisco J. Ayala \\ Department of Ecology and Evolutionary Biology, University of California. U.S.A.
}

\section{RESUMEN}

David Hull, uno de los filósofos de la biología más destacados en la actualidad, propone una "Teoría general de evolución" que, afirma, explica tanto la evolución de los seres vivos como el desarrollo del conocimiento científico. En el caso de la evolución conceptual, Hull sostiene que la competencia entre científicos juega un papel esencial en el avance de la ciencia, de manera similar a lo que ocurre en la evolución biológica. Entre otras cuestiones Hull recupera la tradición de la sociobiología para la explicación del comportamiento aparentemente altruista de los científicos en la búsqueda del conocimiento.

\begin{abstract}
The eminent philosopher of biology, David Hull has proposed that a "general theory of evolution" can be advanced that would account for the evolution of organisms as well as for the evolution of scientific knowledge. According to Hull, competition among scientists plays in conceptual evolution a similar essential role as competition among organisms plays in biological evolution. Hull uses the sociobiology tradition to explain the apparently altruistic behavior of scientists in the search for knowledge.
\end{abstract}

\section{INTRODUCCIÓN}

Nuestra intención en este trabajo es discutir el interés y la validez que tiene la aplicación del darwinismo al análisis del desarrollo del conocimiento científico. En- 
tre las diversas propuestas de epistemología evolucionista ${ }^{1}$ hemos dado un punto de vista desde el evolucionismo sobre las de Stephen Toulmin, Karl Popper y David Hull $^{2}$. Ahora presentamos algunos comentarios sobre los inicios de la concepción de Hull: la elaboración de una analogía sociobiológica.

Como otras epistemologías naturalizadas ${ }^{3}$, la epistemología evolucionista considera que la ciencia puede ser abordada como un objeto natural, por lo tanto como un problema que puede analizarse con una metodología científica. Su particularidad es que además considera que al ser un objeto que se transforma en el tiempo puede ser explicado por el evolucionismo biológico ${ }^{4}$. Nuestro interés en concepciones epistemológicas que como la de Hull utilizan de manera heurística la teoría de la evolución se basa en la preponderancia de tales teorías en la filosofía de la ciencia contemporánea, preponderancia debida en buena parte a su originalidad en reconocer los paralelos entre la evolución de los organismos y la historia del conocimiento científico.

La concepción de David Hull ${ }^{5}$ se desarrolló en dos etapas; en la primera constituyó una analogía casi literal entre la evolución biológica y la evolución del conocimiento; en la segunda elaboró una teoría general de evolución que engloba ambos procesos. Hemos comentado en los trabajos antes citados, que Hull considera necesario que dicha teoría general de evolución abarque todos los procesos de transformación que involucran selección. En síntesis, plantea que los linajes (biológicos o conceptuales) se producen por selección diferencial de los interactores (organismos o

\footnotetext{
1 Aunque la posibilidad de extender el darwinismo a campos diferentes a la evolución —en particular a la explicación del desarrollo del conocimiento- se discute desde tiempos de Darwin, por ejemplo con Thomas Huxley, puede considerarse a Donald Campbell como fundador de la epistemología evolucionista moderna. Plotkin (1994, Darwin Machines, Harvard University Press, Cambridge, Massachusetts) presenta las aproximaciones seleccionistas de Darwin a la evolución de las lenguas y de Huxley al desarrollo de las ideas.

2 RuIZ, R. y F. J. AyAlA, (1993), La concepción epistemológica de David Hull: ¿Existe una ciencia de la difusión de teorías? Arbor 563:9-29; RuIZ, R, Y F. J. AYALA, (1996), El método en la ciencias, epistemología y evolución, Fondo de Cultura Económica, México, (en prensa).

3 Quine, W. V. (1969), "Epistemology Naturalized", in W. V. Quine (ed), Ontological Relativity and Other Essays, New York: Columbia University Press.

4 Para un análisis de la relación entre epistemologías naturalizadas y cvolutivas, véase W. BECHTEL, (1990) "Toward Making Evolutionary Epistemology Into a Truly Naturalized Epistemology", en N. Rescher (ed.) Evolution, Cognition, and Realism, University Press of America, New York.

5 HuLl, D. (1978) "Altruism in Science: A Sociobiological Model of Cooperative Behavior" in The Metaphysics of evolution, State University of New York Press, Albany. Hull, D.; HuLl, D. (1988a). "A Mechanism and Its Metaphysics: An Evolutionary Account of the Social and Conceptual Development of Science" Biology and Philosophy 3:125 -155; Hull, D. (1988b). Science as a Process. An evolutionary Account of the Social and Conceptual Development of Science. Univ. Chicago Press. Chicago and London; Hull, D.-(1990), "Conceptual Selection" Philosophical Studies 60:77-87; HuLl, D. (1992), "An Evolutionary Account of Science: A Response to Rosenberg's Critical Notice", Biology and Philosophy 7:229-23;
} 
científicos) dependiendo del tipo de replicadores que los caracterizan; a su vez, esta selección provoca la reproducción diferencial de replicadores (genes, teorías). ${ }^{6}$

Igual que otras concepciones similares ${ }^{7}$, la contribución de Hull se incluye en el programa de investigación que Michael Bradie ${ }^{8}$ ha llamado Epistemologías Evolutivas Teóricas (EET). Bradie distingue dos programas de investigación que tienen como objeto de estudio el desarrollo del conocimiento. Llama "Epistemología Evolutiva de los Mecanismos Cognoscitivos", (EEM) al programa que intenta explicar la evolución y características de los mecanismos cognitivos en animales y humanos. Este programa considera que dichos mecanismos han evolucionado en la misma forma que el resto de caracteres biológicos: por ello la aplicación del darwinismo es simplemente una extensión, no requiere de ninguna modificación especial. El otro programa, el análisis de la evolución de las ideas (EET) incluye las epistemologías, que como antes se menciona, basan su argumentación en la viabilidad de construir una analogía entre la evolución biológica y la evolución conceptual. Aquí sí, se trata de una extrapolación de una teoría biológica a un campo distinto, el estudio del desarrollo del conocimiento. Aunque no estamos convencidos de que el darwinismo -al menos en su forma actual- pueda explicar la evolución conceptual, coincidimos con los epistemólogos evolucionistas en que existen algunos aspectos analógicos entre ambos tipos de evolución y por lo tanto en que la comparación tiene un carácter heurístico.

Entre los dos programas de investigación anteriores hay un vacío, ninguno de los dos analiza la transformación de los procesos mentales que posibilitan la construcción de conocimiento. Esta problemática es intermedia entre la evolución de los ór-

6 En nuestro (1996) hemos señalado que cada uno de estos conceptos, linaje, interactor y replicador se aplica a más de una entidad, así por ejemplo puede hablarse de linajes de ideas o teorías pero también de linaje de científicos.

7 Donald T. Campbell (1960), Blind Variation and Selective Retention in Creative Thought and in Other Knowledge Processes, Psychological Review 67:380-400; y (1974), "Evolutionary Epistcmology", en The Philosophy of Karl Popper, Vol. I, P.A. Schilpp (ed.). La Salle, Illinois: Open Court, pp. 413-463. STEPHEN TOULmin (1967) The Evolutionary Development of Natural Science American Scientist 55:456-471; (1972). Human understanding. Princeton University Press. Princeton y (1981). "Evolution, Adaptation, and Human Understanding", en Scientific Inquiry and the Social Sciences: A volume in Honor of Donald Campbell. M.B. Brewer and B.E. Collins (eds.).Jossey -Bass, San Francisco, pp. 18-36. K. POPPER, (1977), en Popper and J. C. Eccles, The Self and its Brain, Routledge \& Kegan Paul. Boston y (1985), "Against the Sociology of Knowledge" en Popper Selections, David Miller, edit. Princeton, New Jersey). Robert Richards RichardS, R. J. (1981), "The Natural Selection Model and Other Models in The Historiography of Science". In, Knowing and Validation in the Social Sciences, ed. M. Brewer and B. Collins, 37 -76. San Francisco: Jossey-Bass y (1987), Darwinism and the Emergence of Evolutionary Theories of the Mind and Behavior, Chicago University Press, Chicago.

8 BRAdie, M. (1986), Assessing Evolutionary Epistemology, Biology and Philosophy 1:401-469; Bradie, M. (1990), The Evolution of Scientific Lineages Philosophy of Science Association, 2:245-254 
ganos de los sentidos y el cerebro, por ejemplo, y la evolución de las teorías científicas. Es claro que la evolución orgánica se basa en la heredabilidad de las variaciones y su ulterior selección; es igualmente claro que no hay herencia biológica involucrada en la transmisión de las ideas pero los epistemólogos evolucionistas plantean que una selección similar a la selección natural orienta el desarrollo de la ciencia. Sin embargo, se ignora si puede haber formas de pensamiento innatas que puedan jugar un papel en la adecuación diferencial de los humanos. Por ello, desde nuestro punto de vista, los autores con la preocupación por esta temática evolucionista se encuentran entre quienes constituyen un tercer programa de investigación en epistemología evolucionista. Siguiendo la terminología de Bradie debería llamarse Epistemología Evolutiva de los Procesos, (EEP) cuyo objeto de estudio no está incluido ni en el análisis de los caracteres biológicos que hacen posible el conocimiento (EEM) ni en el análisis del proceso de construcción del saber (EET). Ruse ${ }^{9}$ y Goldman ${ }^{10}$, entre otros, se interesan por el análisis de esta parte.

Ruse $^{11}$ ha planteado dudas ${ }^{12}$ sobre la legitimidad del programa EET, pues sostiene que son tantas las diferencias entre la evolución biológica y la conceptual que "por muy esclarecedora que pueda ser la analogía del cambio orgánico/cambio científico desde un punto de vista heurístico, se desmorona al nivel de la justificación debido a la diferencia existente en sus respectivas variaciones. La evolución científica no es darwinista. No existe justificación alguna para concluir que la ciencia está al mismo nivel que los organismos. Ni tampoco tenemos que aceptar como un hecho probado que las teorías científicas existen sólo porque han derrotado a todas las demás"13. Para Ruse, la ciencia, no tanto las teorías en sí, sino las formas de pensamiento que posibilitan su planteamiento, tienen un valor adaptativo. "Tomar seriamente a Darwin", significa demostrar que hay diferencias en cuanto a procesos mentales y que tales diferencias provocan que los individuos tengan mayor o menor adecuación. Es decir, sostiene que como otras características los procesos mentales influyen en el resultado de la selección natural: "por ejemplo, el teorema pitagórico nos parece obligado, no porque refleja una verdad eterna sino porque de nuestros posibles ancestros los que tomaron seriamente la geometría euclidiana se reprodujeron más que nuestros posibles ancestros que fueron indiferentes a los problemas plantea-

9 RUSE, M., (1987), Tomándose a Darwin en serio, Salvat, Barcelona y (1988) Philosophy of Biology Today State University of New York Press, Albany.

10 Goldman, A. H., (1990), Natural Selection, Justification, and Inference to the Best Explanation, en N. Rescher (ed.) Evolution, Cognition, and Realism, University Press of America, New York.

11 RuSE, (1987), op. cit.

12 Más recientemente, Ruse se ha incorporado al programa de investigación de EET, sin abandonar el que aquí hemos llamado EEP. Véase RuSE, (1990) "Does Evolutionary Epistemology Imply Realism?" en N. Rescher (ed.) Evolution, Cognition, and Realism, University Press of America, New York.

13 RUSE, (1987),p.72 
dos por el espacio"14. Por lo tanto la epistemología evolucionista debe centrar su investigación en los caracteres que propician dicha diferencia en adecuación, en palabras de Ruse, con las reglas epigenéticas que subyacen en la metodología científica $^{15}$; igual que hay reglas epigenéticas que subyacen en otras adaptaciones, "la capacidad de razonar debe ser similar a otros resultados de la adaptación, por ejemplo, las manos" 16 .

Goldman, ${ }^{17}$ como parte de esta tradición, opina que el cerebro humano, o los genes que lo producen, pueden haber sido seleccionados debido a ciertas capacidades cognitivas (además de las perceptuales), por ejemplo, patrones de inferencia o razonamiento: "Apelar a estas capacidades, incluyendo habilidades para razonar o inferir en ciertas maneras, puede entonces constituir un puente en la polémica de los epistemólogos entre apelar al cerebro como un órgano naturalmente seleccionado y la justificación de varios tipos de creencias generadas a través de la operación de dichas capacidades y las estrategias de inferencia que las realizan. Puede haber un valor de sobrevivencia pequeño o ninguno adjunto a las teorías científicas sofisticadas; pero si hay un valor de sobrevivencia para los mecanismos cognitivos que las producen, si este valor está ligado a la capacidad de producir creencias verdaderas en ciertos contextos, y si hay razón para pensar que tal capacidad se extiende y es refinada por contextos y métodos científicos, entonces apelar a estos mecanismos puede ligar teoría evolutiva y justificación epistémica". La pregunta que intentan resolver Goldman y Ruse es ¿cuáles son las ventajas selectivas de la capacidad de razonamiento científico?

Ruse y Hull concuerdan en que uno de los problemas centrales de la epistemología evolucionista es explicar la adecuación (fitness) de las ideas, es decir, explicar porque unas tienen mayor capacidad de sobrevivencia y reproducción que otras; igualmente coinciden en que esta adecuación diferencial no se debe al grado de aproximación de una teoría a la realidad. La diferencia es que Hull entiende por adecuación (fitness) de una teoría el número de científicos que la sostienen; este número indica el número de veces que una teoría se ha reproducido. En cambio Ruse, con su idea de tomar en serio a Darwin, busca los efectos que puede tener una forma de pensamiento en la reproducción diferencial no de las ideas sino de los portadores de las ideas, y no como científicos sino como seres vivos; considera que todo lo que

14 RUSE, (1988), p. 73

15 Ruse utiliza el término de "regla epigenética" que fue acuñado por C. LUMSDEN y E.O. WILSON (1981), Genes, Mind, and Culture, Harvard University Press, Cambridge, Mass. para referirse a las regularidades en el desarrollo. Se relaciona con el concepto de epigénesis (interacción entre los genes y el ambiente que da como resultado el fenotipo).

16 RUSE, (1987), p. 208

17 Goldman, (1990), op. cit. 
creemos y pensamos es un esqueleto mental que existe porque confiere o confirió ventajas adaptativas en los humanos ${ }^{18}$. Ruse confía en que una buena teoría (en tanto apegada a la realidad, pues aquí los errores cuestan la vida o al menos la disminución de la capacidad reproductiva) y sobre todo una forma correcta de razonamiento (por la misma razón), darán mayor eficacia biológica a quienes creen en ella ${ }^{19}$. Hull, por su parte, atribuye una racionalidad tal a la comunidad científica que considera que impedirá que se incline por teorías erróneas. Por lo anterior ni Hull ni Ruse establecen criterios de evaluación acerca del contenido de verdad de una teoría.

\section{DE LA ANALOGÍA A LA TEORÍA}

Como antes señalamos, antes de decidirse a construir una teoría general de evolución, Hull trabajó en la elaboración de una analogía explicativa entre evolución biológica y evolución conceptual. En esta etapa se proponía presentar una explicación análoga para las relaciones sociales peculiares que existen entre científicos: "Así como aparece ambivalencia cuando un organismo debe cooperar con sus competidores sexuales, aparece una ambivalencia comparable cuando un científico tiene que cooperar con sus competidores científicos. En ciencia, sin embargo, el objetivo último no es la transmisión de genes sino de ideas. Los científicos se comportan tan egoístamente como lo hacen debido a que es en su propio interés hacerlo. Lo mejor que un científico puede hacer para su carrera es lograr que sus ideas sean aceptadas por sus compañeros científicos"20. Así mismo, defendió la validez científica de construir tal analogía: "Algunos pueden objetar mi uso de los procesos de evolución biológica como análogos del desarrollo de la ciencia. Si la objeción es que he razonado analógicamente, entonces no tengo disculpas que dar. Razonar por analogía ha sido parte integral de la ciencia desde sus orígenes. Si la objeción es que la evolución biológica no es un modelo adecuado para la evolución de las ideas, entonces la objeción puede tener substancia"21. Para Hull es tan válido establecer la analogía entre desarrollo científico y biológico como extrapolar el darwinismo a otros fenómenos como la respuesta inmunológica; argumenta que la reacción del sistema inmune a los antígenos es un caso de proceso de selección que difiere tan radicalmente de la se-

\footnotetext{
18 RUSE (1988), p. 73).

19 "Nuestros instrumentos de conocimiento - nuestros sentidos, nuestro cercbro, nuestras habilidades lingüísticas - no fueron desarrolladas para darnos una imagen desinteresada de la realidad, sino para ayudarnos a sobrevivir y reproducirnos." RUSE, 1990, op. cit.

20 HULl (1978), op. cit. p. 243

21 Hull (1978), op. cit. p. 262.
} 
lección natural basada genéticamente como difiere ésta de los cambios conceptuales en ciencia 22 .

Cuando se planteó construir una teoría general2.3 que explicara ambos fenómenos evolutivos en virtud de que los dos son procesos selectivos, aclaró por qué pasó de una analogía a una teoría general: "mi intención no es razonar analógicamente de la evolución biológica a la evolución social y conceptual, sino identificar características generales de los procesos de selección como tales. Los efectos de grupos pequeños en tasas de cambio deben ser los mismos independientemente de que dichos grupos consistan de organismos intercambiando su material genético o de científicos intercambiando los resultados de su investigación"24. La posibilidad de construir tal modelo, justifica Hull, se da porque la ciencia - al igual que otras entidades- puede ser aproximada científicamente, es decir, hay una ciencia de la ciencia. Presenta regularidades que posibilitan hacer afirmaciones parecidas a leyes: "La ciencia debe ser tratada como algo natural, una manera de conocer sobre la cual se pueden hacer proposiciones"25. Algunos autores como Dupré26, consideran que teorías como la de Hull no son una teoría general de evolución sino una "débil metáfora" entre el desarrollo del conocimiento y la evolución biológica. Hull ha respondido que intenta analizar los procesos de selección de forma que sea suficientemente general que incluya todos los tipos de selección - evolución biológica, la respuesta de los sistemas inmunes a antígenos, el desarrollo del sistema nervioso y los cambios conceptuales en ciencia- pero no tan general que no tenga contenido empírico ${ }^{27}$. El contenido empírico al que refiere Hull es la evidencia que aporta la historia de la ciencia: por ello en Science as a Process analiza el comportamiento de grupos rivales de taxónomos, los cladistas y los feneticistas.

De manera similar a Darwin, quien pudo transformar anomalías en instancias confirmadoras, y que así explicó gran número de fenómenos biológicos, Hull se propone "en lugar de explicar los hábitos de los esclavos de hormigas, explicar por qué los científicos en ocasiones se comportan tan altruistamente, por ejemplo, dando crédito a sus más cercanos competidores, y por qué en otras ocasiones no lo hacen. ¿Bajo que condiciones están dispuestos a dar crédito a otros cientílicos, y bajo que

22 "After all, the reaction of the immune system to antigens is an instance of a selection process which differs just as radically from gene based natural selection as does conceptual change in science. Any analysis of selection processes must apply to it as well as to natural selection" (HULL, (1988a), p. 124)

23 (1988)a, op. cit. (1988)b, op. cit.

24 HULL (1988)b, p. 287

2.5 Hull (1990), p. 78

26 DuprÉ, J. Scientific Pluralism and the Plurality of the Sciences: Comments on David Hull's Science as a Process, Philosophical Studies vol. 60, p.61-76.

27 Hull, (1990), op. cit. p. 79 
condiciones están dispuestos a reclamar prioridad para ellos mismos?28 Como en otras actividades humanas, los científicos negocian: "La ciencia es tan organizada que los científicos están obligados a negociar crédito por apoyo"29. Esta negociación es importante, pues para ganar apoyo un científico necesita mostrar que su investigación descansa en investigaciones anteriores; pero este reconocimiento le resta originalidad a su trabajo. "Uno no puede ganar apoyo de un trabajo particular a menos que lo cite, y al citarlo automáticamente se confiere valor al trabajo citado y se resta originalidad al propio trabajo. Los científicos quisieran crédito total y respaldo masivo, pero no pueden tener ambos" (Ibidem).

Entre las observaciones que Hull utiliza para fundamentar su teoría están, en primer lugar, que la ciencia es una de las actividades con mayor éxito en el cumplimiento de sus objetivos - para la ciencia el descubrimiento de la verdad, para los científicos tener sus ideas propias aceptadas en el cuerpo general de conocimiento cientílico aceptado-: "Una característica de la ciencia que nos deja perplejos, es que trabaja tan bien en el logro de sus objetivos manifiestos, mucho mejor que cualquier otra institución social"30. Una de las razones de este éxito es que la ciencia como otras instituciones sociales tiene sus normas, pero que son respetadas en un grado mayor que en otras profesiones. La diferencia entre la ciencia y otras profesiones, como medicina, enseñanza, actividades policiacas, etc., es el grado en el que cada una logra sus objetivos, independientemente del tiempo que cada una dedica a ocuparse de sí misma $^{31}$. "Por definición, las profesiones son ocupaciones que se autoregulan y mantienen en orden. Una cosa es clara entre las profesiones: por lo general no se auto vigilan muy bien, al menos no de acuerdo con el criterio que profesan. Sin embargo los científicos se vigilan entre sí como si la ciencia estuviera hecha sólo de chismes de vecinos"32

Hull admite que uno de los objetivos fundamentales de la ciencia es alcanzar la verdad. Sin embargo se pregunta: "Si descubrir la verdad es todo lo que importa, ¿Por qué es tan importante quién lo hizo primero? ¿Por qué han desarrollado los científicos tan intrincada etiqueta para las citas? ¿Por qué los científicos se enredan en disputas de prioridad que sobrepasan en acritud incluso a los procesos de divorcio? ¿Están los científicos realmente menos preocupados por la ganancia y la gloria personal que nadie más?"33. De la misma forma se pregunta si la ciencia mantendría

28 Hull, (1988)a, op. cit. p.126

29 HuLl, op. cit. 1988a, p. 127

30) HuLl, (1988)a, op. cit. p. 125

31 "The difference between science and the professions mentioned, is the degree to which it fulfills its stated goals, the time spent looking after itself notwithstanding" HULL, (1978), p. 251.

32 HuLl, (1988)a, op. cit. p. 128

3.3 Hull, (1978), op. cit. p. 244 


\section{LA ANALOGÍA SOCIOBIOLÓGICA DEL DESARROLLO DE LA CIENCIA}

su carácter auto-reforzante si el reconocimiento explícito fuera abandonado completamente por el reconocimiento tácito que es consecuencia del uso del conocimiento, o si los científicos consistentemente recibieran poco o ningún reconocimiento hasta después de su muerte ${ }^{34}$. Es decir, en opinión de Hull, el sistema de premios y castigos funciona tan bien en ciencia que posibilita el alcance de sus objetivos: "Si la intención manifiesta de la ciencia es incrementar nuestro conocimiento del mundo empírico, ... entonces, la estructura social de la ciencia está bien calculada para lograrlo. Los científicos, como los miembros de todas las profesiones, deben gastar una cantidad considerable de energía en su auto-mantenimiento. Deben ser captados nuevos miembros, las fuentes de recursos explotadas y establecidas las bases de poder en la sociedad. Pero ninguna de estas actividades es incompatible con la afirmación de que los científicos, en su investigación, buscan la verdad por su valor en sí misma"35.

\section{EPISTEMOLOGIA Y SOCIOBIOLOGIA}

Desde el punto de vista sociológico, las diferencias en el comportamiento entre los individuos que participan en las diversas instituciones pueden ser explicadas en términos de la estructura social de esas instituciones. Según Hull, de manera similar a como la sociobiología explica que el aparente altruismo es en realidad egoísmo genético, el aparente interés en descubrir la verdad es, en realidad, el deseo de los científicos de ver reproducidas sus ideas el mayor número de veces posible: “... razones suficientemente egoístas deben involucrar las usuales ganancias en dinero, posición y fama, pero en ciencia hay una fuerza directriz aún más fuerte: la incorporación de las ideas de uno en el cuerpo del conocimiento científico generalmente aceptado. La razón de que la ciencia trabaje tan bien, es que el logro de este egoísta fin por parte del científico individual está bien calculado para alcanzar el objetivo manifiesto de la ciencia como institución"36.

No obstante ser una actividad egoísta, la ciencia es también una actividad altamente cooperativa; de acuerdo con el planteamiento de Hull, las prácticas sociales peculiares que se han desarrollado en ciencia para facilitar la cooperación entre competidores, son exactamente las que deberían haber si el principal objetivo en ciencia es tener nuestras ideas incorporadas en el cuerpo del conocimiento científico aceptado. "Así como los biólogos explican la estructura social de los grupos con relaciones de parentesco, refiriéndose al flujo genético, yo deseo argumentar que la mejor ma-

34 Hull, (1978), op. cit. p. 254

35 Hull, (1978), op. cit. p. 251

36 Hull, (1978), op. cit. p. 251 
nera de entender la ciencia es seguir el flujo de ideas. Los fenómenos con los que yo trataré, serán las formas en las que los científicos se vigilan a sí mismos, se premian, la coincidencia en ciencia entre los fines manifiestos de la institución y los objetivos del científico individual, la eficacia de los objetivos internos de la ciencia contra los objetivos externos como dinero y reconocimiento y el papel del sistema de citas en la organización social de la ciencia" 37 .

La vigilancia permanente entre científicos es una característica fundamental de la estructura social de la ciencia. Esto no ocurre, por lo menos no en la medida en que lo hacen los científicos, en profesiones como la policía, la medicina y la enseñanza. "Los investigadores" señala Hull, "se vigilan entre sí, fría, desapasionada, casi cruelmente" 38 . Se vigilan, porque a diferencia de lo que ocurre en otras actividades, en ciencia el bien del científico y el de la ciencia no son contradictorios: "Los científicos se adhieren a las normas de la ciencia tan bien, porque frecuentemente es en su mejor interés hacerlo. En general, lo que es bueno para el científico es realmente bueno para el grupo. La mejor cosa que un científico puede hacer por la ciencia como un todo, es luchar por incrementar su propia adecuación inclusiva conceptual"39. Esta lucha por ganar adeptos, es mantenida en ciertos límites por dos factores: la necesidad de los científicos de usar el trabajo de otros y la posibilidad de comprobación empírica.

En orden a evaluar la forma en la que esos factores funcionan en ciencia, Hull distingue dos maneras en las que un científico puede "pecar" contra los principios de la ciencia. La primera es por la publicación de datos falsos, sea intencional o no intencionalmente ("mentir"). La segunda y más común es la falta de crédito donde debe darse crédito ("robar") ${ }^{40}$. Hull retoma la idea de Robert K. Merton ${ }^{41}$ de que la competencia y las disputas de prioridad son parte integral de las relaciones sociales entre científicos. Así mismo, admite con Cole y Cole ${ }^{42}$ que las dos formas de comportamiento desviado en ciencia, robar las ideas de otro científico y publicar datos falsifi-

37 HuLl, (1978), op. cit., p. 250

38 HULL, op. cit., (1978), p. 252

39) Hull, op. cit., (1988)a, p. 129

40) "Such striving is kept within certain bounds by two factors: the need of scientists to use each other's work and the possibility of empirical testing. However, in order to evaluate the manner in which these factors function in science, two ways in which a scientist can 'sin' against the mores of science must be distinguished. The first is by publishing faulty work, whether intencionally or unintencionally ('lying'). The second and most common is the failure to give credit where credit is due ('stealing')" HULL, (1988)a, op. cit. p. 129

4 Merton, R. K. The Sociology of Science. University of Chicago Press, Chicago.

42 COLE, J. R., and S. COLE (1973), Social Stratification in Science. University of Chicago Press, Chicago. 
cados, son raros comparados con el visible comportamiento incorrecto en otras instituciones. ${ }^{43}$

Desde el punto de vista de Hull, en ciencia es peor mentir que robar; mentir es además menos frecuente. En la diferente actitud hacia estos "pecados", Hull encuentra una característica particular de la ciencia que ha posibilitado su éxito como actividad social: la búsqueda, por diferentes medios, del bien general del conocimiento. A la pregunta ¿,por qué es mucho más raro en ciencia mentir que robar? Hull contesta que mentir es castigado más severamente porque mientras el robo daña solamente a la persona cuyo trabajo ha sido robado, mentir perjudica a cualquicra que use ese trabajo, lo que implica un daño general a la ciencia. Las contribuciones asignadas equivocadamente a un autor son tan útiles como aquéllas cuya autoría se asigna correctamente ${ }^{44}$. Por supuesto, Hull defiende que si robar conocimiento fuera generalizado el sistema sería afectado, pues también es importante para su teoría el hecho de que los científicos buscan el reconocimiento de su comunidad. Sin embargo, la publicación de datos falsos daña a la propia ciencia pues en general los científicos confían en la moralidad de sus colegas; por ello, por lo regular utilizan los datos publicados sin probarlos: "Si un descubrimiento particular apoya su propia investigación, son capaces de incorporarlo sin comprobarlo. La comprobación está reservada para aquellos descubrimientos que amenazan la investigación propia"45. Probar cada dato haría prácticamente imposible el avance en ciencia; precisamente la ventaja del trabajo conjunto de los científicos es compartir recursos conceptuales. La organización social de la ciencia posibilita esta confianza, pues los científicos que tienen diferentes perspectivas serán los que se encarguen de poner a prueba dichos datos: "Los científicos que trabajan fuera de tu grupo de investigación son perjudicados si adoptan tus puntos de vista equivocados pero, más importante, están también en una mejor posición que tú para exponerlos a las pruebas más severas. Sus intereses de carrera no son dañados si tus puntos de vista son refutados"46. Al contrario, en ciencia se premia el mostrar los errores sean propios - lo cual no es común-o de otros científi$\cos$.

Como vemos, el argumento de Hull es que la estructura de premios y castigos en ciencia posibilita que el interés general esté por encima del interés individual, pues si no estuviera tan castigado publicar datos adulterados los cientílicos no podrían confiar en los datos de sus colegas y esto retrasaría el avance de la ciencia. Esto, desde nuestro punto de vista, hace a la ciencia una actividad social menos egoísta que otras.

\footnotetext{
4.3 "They are rare because they generally are not effective in attaining success and because most scientists seem to have a genuine commitment to the norms" (HULL, (1978), op. cit. p. 246).

44 HULL, op. cit. (1988)a, p. 130

4.5 HuLl, (1988)a, op. cit., p. 131

46 Ibidem
} 
Es decir, en el nivel individual los científicos pueden presentar una actitud egoísta pues independientemente de que un científico tenga la fama de robar las ideas de otros, como señala Hull, si su trabajo es bueno otros científicos lo usarán, "el uso que un científico puede hacer del trabajo de otro es el modus operandi de la ciencia"47. Igualmente, los científicos dan crédito porque buscan que otros a su vez les reconozcan sus méritos (altruismo recíproco), y seguramente tienen otras actitudes egoístas, pero el resultado global de su trabajo, la ciencia, no es egoísta en tanto que como puede verse en el propio análisis de Hull, este tipo de actitudes protegen a la ciencia. Lo que es discutible es que del estudio del comportamiento de las comunidades científicas infiera la estructura de la propia ciencia. No puede igualarse ciencia a comunidad científica. Aunque están obviamente ligadas no pueden confundirse. Del comportamiento egoísta de los científicos no puede concluirse "que la ciencia es egoísta"48. Una cuestión evidente es que la evolución de los seres vivos es resultado de la selección natural de variantes hereditarias. La selección natural determina cuáles organismos serán los triunfadores en la lucha por la existencia (entendida como la suma de todas la interacciones bióticas y abióticas) favoreciendo su sobrevivencia y reproducción. El equivalente en evolución conceptual sería que las ideas o teorías participaran en una lucha por la existencia en la que las ideas más adecuadas - entendidas en función de su interacción con la realidad, de su capacidad de representar la parte de la naturaleza que tratan de explicar, es decir de su cercanía a la verdadfueran las que se reprodujeran con mayor éxito. La teoría de Hull, introduce un criterio cuantitativo a la evaluación de las teorías científicas, pero no necesariamente las teorías más aceptadas son las teorías más acertadas. Parece ocurrir lo opuesto a lo que ocurre en ciertas especies, donde unos individuos aparentemente altruistas no se reproducen (las castas obreras en himenópteros, por ejemplo) pero cuidan a los descendientes de la reina con la que comparten genes; de esta manera sus genes se perpetúan, es decir su comportamiento aparentemente altruista produce un resultado claramente egoísta. En el caso de los científicos cada uno busca reproducir sus ideas sea como individuo o como parte de un demo conceptual pero el resultado final es la reproducción no necesariamente de sus ideas sino las de los científicos que la comunidad científica avala. Es decir, su comportamiento claramente egoísta produce un resultado altruista, el avance de la ciencia; posiblemente sin la incorporación de las propias ideas del científico egoísta, esto es, por más egoísta que sea y haga lo imposible por tener una gran adecuación inclusiva (igual que las abejas obreras al cuidar a los hijos de su hermana la reina) y así tratar de convencer al mayor número de científicos posible del valor de sus teorías, la decisión final la tomará la comunidad científica. No depende sólo de capacidad de convencimiento. La suma total de comporta-

47 HuLL, (1978), op. cit., p. 256

48 HULl, (1988)b, op. cit., p. 432 
mientos individuales egoístas en ciencia da por resultado que la ciencia no sea egoísta: esto es lo que habría que explicar. En el mismo sentido, Popper señala que la subjetividad individual de los científicos es convertida en objetividad por ser la ciencia una actividad social: "lo que llamamos 'objetividad científica' no es el producto de la imparcialidad de los científicos individuales, es el producto del carácter social o público del método científico, y la imparcialidad del científico individual, en tanto existe, no es la fuente sino más bien el resultado de esta objetividad de la ciencia organizada socialmente"49.

\section{¿ALTRUISMO CONCEPTUAL O EGOISMO CIENTÍFICO?}

Como hemos visto, desde el punto de vista de Hull, los científicos compiten entre sí para convencer a otros científicos de las virtudes de sus teorías y de esta manera forman un linaje de científicos que comparten sus ideas. De forma análoga a la manera en que los organismos luchan entre sí por dejar la mayor representación posible de sus genes, los científicos tratan de convencer al mayor número de científicos. $\mathrm{Si}$ los organismos se ocupan ante todo por dejar el mayor número de descendientes, lo esperado es que la lucha entre ellos sea cruenta; los comportamientos altruistas contradicen esta idea general derivada de la selección natural, por lo tanto habría que explicarlos. En términos biológicos se define el comportamiento altruista como aquel que ocasiona la disminución del éxito reproductivo del organismo que lo presenta y a la vez aumenta el éxito reproductivo de otro organismo. En el caso de la ciencia, de acuerdo con el planteamiento de Hull, si los científicos colaboran entre sí no es porque tengan como interés general el avance de la ciencia (si trabajaran sólo por dicho interés general serían altruistas); lo que ocurre es que al promover la aceptación de sus ideas y evidenciar los fallos de otras ideas, posibilitan el avance de la ciencia. Es decir, como consecuencia de una actitud netamente egoísta se produce el desarrollo científico que beneficia a toda la humanidad.

"Por supuesto, los científicos no pasan sus ideas genéticamente, pero sí forman grupos sociales. Tienen estudiantes y discípulos para no mencionar a los asistentes de investigación permanentes, tan cercanos a los organismos eusociales no reproductivos como un humano puede ser. Por supuesto, el flujo de ideas científicas es diferente como para corresponder muy cercanamente al flujo genético, pero como incluso los científicos están prestos a admitir, sus verdaderos 'hijos' son sus ideas, y los principales medios por los cuales los científicos transmiten sus ideas son otros científi-

49 POPPER, (1985), op. cit., p. 374 
$\cos ^{150}$. Por lo tanto se puede hablar de que los científicos, como los organismos, tiene una adecuación en función del número de descendientes que dejan.

Hull se refiere no sólo a la idea tradicional de adecuación (fitness), es decir a la idea de adecuación individual, sino que retoma las nociones de adecuación inclusiva y de selección por parentesco (kin selection) derivadas de J. B. S Haldane ${ }^{51}$, William Hamilton ${ }^{52}$, Robert Trivers ${ }^{53}$ y otros. De acuerdo con esta corriente, la cooperación fenotípica entre parientes puede ser mejorada por dos mecanismos, selección familiar y altruismo recíproco ${ }^{54}$. Hull se propuso mostrar que los científicos que tienen ideas comunes se comportan de manera similar a los organismos que presentan genes comunes: "Intento usar la parte más controvertible de la explicación biológica del comportamiento animal (cuidado parental y selección familiar) como modelo para una teoría social de la estructura de la ciencia. Por supuesto, ser un científico exitoso puede ser tan ventajoso para la propia descendencia como el ser exitoso en cualquier otra ocupación, pero los científicos no transmiten sus ideas a través de sus genes. Algunos aspectos del comportamiento cooperativo entre los científicos deben ser tan explicables en términos de altruismo recíproco como lo es la regurgitación entre los perros africanos, y como la tendencia humana a aprender acerca del mundo en el que vivimos puede estar tan genéticamente basada como la facilidad con la que podemos ser indoctrinados" 55 .

La idea de selección por parentesco, implica que los organismos pueden tener comportamientos altruistas con sus parientes en función de que comparten genes con ellos y saldrán beneficiados de dicho comportamiento al favorecer la reproducción de sus propios genes. La selección natural favorece el comportamiento altruista si el altruista con ese comportamiento favorece la reproducción de sus parientes más cercanos. (Haldane bromeó con esto diciendo que él sacrificaría su vida por dos hermanos, cuatro tíos o por ocho primos). Este interés en la perpetuación de los propios genes, aún a través de otros individuos, implica que este tipo de comportamiento es en realidad egoísta. No es verdadero altruismo ayudar para obtener un beneficio: "De acuerdo con el uso biológico de estos términos, la intención es irrelevante; todo lo que importa es el efecto. Si el efecto de un comportamiento es benéfico a la sobrevivencia personal del organismo, entonces [dicho comportamiento] es fenotípicamente

5) HULl, (1978), op. cit., p. 261

51 Haldane, J. B. S. (1932). The Causes of Evolution, Longmans, London, New York.

52 W. D. Hamilton, (1964). The Genetical Theory of Social Behavior. Journal of Theoretical Biology 7:1-51

53 R. L. TRIVERS, (1971). The Evolution of Reciprocal Altruism. Quarterly Review of Biology 40:35-57 y (1985), Social Evolution, Benjamin/Cummins Publ. Co., Menlo Park.

54 B. Voorzanger, (1994), Bioaltruism Reconsidered, Biology' and Philosophy', 9:75.84 hace una interesante revisión de estos conceptos.

55 HULl, (1978), op. cit., p. 250 
egoísta; si beneficia la sobrevivencia de algún otro organismo, cs fenotípicamente altruista. Si el efecto de un comportamiento es incrementar la probabilidad de transmisión de réplicas de sus propios genes o su duplicación en otros organismos, entonces es genéticamente egoísta; si incrementa la probabilidad de transmisión de genes de diferente tipo de los propios, entonces es genéticamente altruista"56.

En función de que los organismos cercanamente relacionados contienen copias de los genes unos de otros, diversos grados de cooperación pueden ser esperados entre parientes genéticos. Algunos organismos producen numerosos descendientes, tantos como es posible. Su inversión en el futuro es solamente en término de números. Otros tienen menos descendientes de los que pueden, pero la diferencia está en el cuidado que dedican a su hijos. Este último tipo de comportamiento es fenotípicamente "altruista" pero genéticamente "egoísta". Observaciones similares pueden hacerse para hermanos, sobrinos, primos, etc. ${ }^{57}$. En función de la defensa y reproducción de las ideas de un grupo, los científicos forman linajes, constituyen una familia conceptual: "Así como los organismos se comportan de formas que resultan en réplicas de sus propios genes, o duplicados de esos genes en parientes cercanos, siendo así transmitidos a generaciones posteriores, los científicos se comportan en formas calculadas para lograr que sus ideas sean aceptadas como propias por otros científicos"58.

Como puede verse, para explicar el comportamiento aparentemente altruista de los científicos, Hull extrapola el concepto de "altruismo recíproco" de Trivers. Trivers $^{59}$, se refiere a la idea de que un ser humano pueda ayudar a otro en espera de que la persona que recibió la ayuda pueda corresponder en el futuro. El mensaje principal de Trivers es que el efecto neto del altruismo recíproco tiene que ser genéticamente "egoísta ".

Hull sostiene que la adecuación inclusiva y la estructura démica puede aplicarse a las relaciones profesionales entre los científicos: "Los cientílicos son organismos. Están en la misma lucha por pasar sus genes como lo están otros organismos. Son también humanos. Como tales, son parte de una cultura. Ser un cientílico exitoso tiene el efecto entre los científicos que el ser exitoso en otras actividades humanas tiene entre los seres humanos en general. Por ejemplo, en ciertos tipos de sociedad, los individuos de alto rango posponen la paternidad y tienen menos hijos de los que tienen individuos de bajo rango. En dichas sociedades, si la ciencia es una actividad de alto rango, los científicos se comportarán de acuerdo a esta situación"60.

56 Hull (1978), op. cit., p. 247

57 HuLl, (1988)b, op. cit., p. 432

58 HuLl, (1988)a, op. cit., p.126

59) (1971), op. cit.

(1) Hull (1988)b, op. cit. p. 434 
Hull considera que este tipo de relación (formación de linajes) es fundamental para el desarrollo de la ciencia, pues opina que si no hay reproducción de una idea en el sentido de que sea compartida y defendida por un grupo en lugar de un científico sólo, dicha idea no será reconocida y pasará sin ser notada por la comunidad científica. En especial por la relativamente corta duración de la vida de un científico. En fin, para que una idea cuente como contribución genuina, como una "nueva verdad", debe ser parte de una secuencia de replicación. Coincide en este punto con Toul$\min ^{61}$ : "Para que hablemos de una 'variante conceptual' genuina, no es suficiente encontrar algún individuo honesto entretenido en una innovación conceptual; toma algo más que las reflexiones personales de individuos mentalmente abiertos crear un acervo de variantes conceptuales en ciencia"62 .

Respecto a las generaciones que van formando el linaje, Hull propone que cada replicación de una idea, sea en un libro, en una revista o en la mente de un científico, es una generación. No sólo se replican las ideas, también funcionan como replicadores en ciencia "los elementos del contenido fundamental de la ciencia — creencias sobre los objetivos de la ciencia, formas adecuadas sobre cómo alcanzar esos objetivos, problemas y sus posibles soluciones, modos de representación, datos acumulados, y cosas por el estilo-. Estas son la entidades que pasan en las secuencias de replicación. Incluidos entre los 'vehículos' que transmiten dichas secuencias en replicación conceptual están libros, revistas, computadoras, y por supuesto el cerebro humano. Como en la evolución biológica, cada replicación cuenta como una generación con respecto a la selección"63. Un linaje, indica Hull, es una entidad que persiste indefinidamente a través del tiempo en el mismo estado, o en un estado alterado como resultado de la replicación. Linaje es un concepto genealógico, una clase especial de entidad histórica espacio-temporal formada por series de replicación. Y en la medida que la selección es operativa, estos linajes serán formados como resultado de la selección también. Es evidente que, como afirma Hull, si una idea creada por un científico no es retomada por nadie, dicha idea quedará olvidada por lo menos hasta que alguien la rescate y vuelva a desarrollarla. Un caso ejemplar es el de Mendel $^{64}$ : pese a lo importante de su descubrimiento y al brillante tratamiento que hace de un viejo problema, no es comprendido en su época. Sus ideas tienen que esperar más de 30 años para ser reconocidas por los creadores del mendelismo moderno. Queda clara la incapacidad de Mendel para constituir un linaje conceptual; sin embargo la comunidad científica tuvo la capacidad de reconocer el valor del mendelis-

61 Toulmin, (1972), op. cit.

62 Citado en Hull, (1988)b, op. cit., p. 436

6.3 Hull (1988)b, op. cit. p 434

64 Véase F. J. Ayala, (1977), "Philosophical Issues" en Dobzhansky et al. Evolution, cap. 16 Freeman, San Francisco. 


\section{LA ANALOGÍA SOCIOBIOLÓGICA DEL DESARROLLO DE LA CIENCIA}

mo e iniciar tal linaje. Esto muestra que a largo plazo no es fundamental la adecuación conceptual del individuo, ni en un sentido ni en otro. También hay ejemplos inversos en los que un científico puede ser reconocido en su época debido a su gran capacidad de hacer proselitismo y después ser olvidado por completo. Los linajes conceptuales se constituyen por medio del proceso de convencimiento de unos científicos a otros. Un linaje estará formado por aquellos científicos que comparten ideas que son idénticas por descendencia. Es importante aclarar aquí que para Hull si, por ejemplo, un científico llega a ideas similares que otro pero no ha aprendido sus ideas de él no es parte de su linaje. En este sentido Hull recupera la idea de monofilia del cladismo, aunque no directamente la idea de su fundador, Hennig, que consideró que este criterio no funciona a nivel de especie, que sería el equivalente del nivel conceptual del científico que crea una teoría. Es evidente que este criterio es muy extremo pues dos científicos que lleguen a una idea por muy parecida que sea tendrán que ser considerados miembros de diferente demo.

\section{¿EGOISMO CONCEPTUAL O EGOISMO DE LOS CIENTÍFICOS?}

Como consecuencia de la analogía de Hull puede decirse que si los organismos tratan de aumentar la representación de sus genes y los científicos de sus ideas en las generaciones sucesivas, al igual que puede hablarse de genes egoístas, podría hablarse de ideas o teorías egoístas ${ }^{65}$. En todo caso es importante diferenciar entre los factores de selección de ideas y los factores de selección de científicos, pues evidentemente son diferentes. Hull no hace esta distinción entre ciencia (nivel de las teorías) y comunidad científica (los científicos como individuos y como parte de una población de científicos) ${ }^{66}$. La selección de científicos se lleva a cabo a nivel social y es resultado de la lucha que puede ser individual o grupal. En esta lucha, cuentan las características individuales de los científicos y las características del grupo a que pertenecen, por ejemplo, capacidad de tipo político de hacer proselitismo por sus ideas y por supuesto su capacidad científica. Pero esta lucha es de tal estilo, que un científico de gran capacidad científica puede dejar de ser reconocido por su falta de capacidad en política científica, (o simplemente por tener otros intereses, como en el caso de Mendel) y por lo tanto puede incluso pasar desapercibido. La selección de teorías tiene otros parámetros, aquí cuentan las características de la teoría; por ejemplo, su consistencia interna y externa, su contenido empírico, su carácter tautológico

0.5 En este sentido Dawkins habla de genes y memes egoístas.

6o K. Sterelny (1994, Science and Selection, Biology' and Philosophy, 9:45-62). analiza algunos problemas de la no distinción por parte de Hull entre estos dos niveles, en particular la confusión que surge en el manejo de los conceptos de replicador e interactor. 
o no tautológico, si representa o no un avance científico en tanto resuelva más problemas o mejor que sus competidoras, si sobrevive las diferentes pruebas a las que deberá ser sometida. En la comparación de una teoría con sus alternativas se seleccionará aquella que en opinión de la comunidad científica cumpla con las normas aceptadas por esa comunidad. Es decir, no basta con la capacidad proselitista del científico o de su grupo, la teoría deberá presentar determinadas características que la hagan aceptable por la comunidad científica. En suma, a pesar de estar relacionadas, tanto las formas de selección como de aparición de variación son diferentes en estos dos niveles; esto es algo que necesita ser tenido en cuenta en una concepción evolucionista del desarrollo de la ciencia.

Evidentemente, Hull reconoce la existencia de los dos niveles mencionados, y admite que las ideas requieren de los científicos para reproducirse y para interactuar con los problemas que tratan de resolver; sin embargo, no explica las diferencias en su modelo respecto a los dos niveles.

Es importante recordar que, como las teorías, los genes tampoco se replican solos. Igual que las ideas necesitan de los científicos para su reproducción, los genes requieren de la participación de otras moléculas. Sin embargo, ellos dirigen su propia replicación lo cual no hacen las teorías. Rosenberg ${ }^{67}$ acierta cuando señala que los replicadores en ciencia son abstracciones y, desde su punto de vista, los replicadores son entidades con participación causal, por lo tanto no pueden ser abstractos. Por otra parte, Rosenberg destaca que la neurociencia ha mostrado que la relación entre símbolos-creencias y la materia gris que los realiza, es mucho más compleja que la relación entre el gene y las secuencias de polinucleótidos que construye.

Posiblemente pueda ayudar en el análisis de estos dos niveles de evolución la idea de Popper de la existencia de un mundo donde las ideas interactúan de forma al menos parcialmente independiente. Así, mientras los científicos y sus cerebros forman parte del mundo 1 al igual que los genes, las ideas forman parte del mundo 3 . De acuerdo con Popper ${ }^{68}$ el mundo 1 está constituido por los objetos físicos o los estados físicos; el mundo 2, por los estados de conciencia o estados mentales o de las disposiciones de comportamiento a la acción; el mundo 3 es el mundo de los contenidos de pensamiento objetivo, especialmente, de los pensamientos científicos y poéticos y de las obras de arte. Entre los habitantes del "mundo 3" de Popper, están los sistemas teóricos y de igual importancia los problemas y las situaciones problemáticas. Los más importantes, señala Popper, son los argumentos críticos y lo que se podría llamar - por semejanza con los estados físicos o los estados de conciencia-

67 Rosenberg, A. (1992), Selection and Science: Critical Notice of David Hull' Science as a Process, Biology and Philosophy 7:217-228

68 POPPER, (1985), op. cit. p. 106 
el estado de una discusión o el estado de un argumento crítico, así como los contenidos de las revistas, libros y bibliotecas.

Uno los aspectos más importantes de los contenidos del mundo 3 , es que no siempre son resultado de producción planeada por los individuos, por lo tanto tienen una cierta autonomía. Al respecto, Popper ${ }^{69}$ escribe: "Es obvio que las teorías son el producto, por supuesto, del pensamiento humano (o, si se prefiere, del comportamiento humano, no debatiré acerca de términos). Sin embargo, las ideas tienen cierto grado de autonomía ; pueden tener, objetivamente, consecuencias en las que nadic, hasta ese momento, ha pensado, y que pueden ser descubiertas; descubiertas en el sentido en el que una planta o animal hasta entonces desconocidos pueden ser descubiertos. Se puede decir que el mundo 3 es hecho por el hombre es sus orígenes, y que una vez que las teorías existen, empiezan a tener una vida propia: producen nuevos problemas, producen previamente consecuencias invisibles". Popper ejemplifica esta idea con la producción de una teoría científica: "El científico productivo, como regla, empieza con un problema. Dicho científico va a tratar de entender el problema, esta es usualmente una tarea intelectual prolongada - un intento del mundo 2 de asir un objeto del mundo 3. Es cierto que al hacer esto puede usar libros (u otras herramientas científicas en sus materializaciones del mundo 1). Sin embargo, su problema puede no estar establecido en esos libros; más bien puede descubrir dificultades implícitas en las teorías establecidas. Esto puede involucrar un esfuerzo creativo: el esfuerzo de asir la situación abstracta problemática; si es posible, mejor de lo que fue hecho antes. Entonces el científico puede plantear sus soluciones, su nueva teoría. Esto puede ser puesto en forma linguiística en innumerables maneras. El escogerá cualquicra de ellas. Después discutirá críticamente su teoría y podrá modificarla como resultado de la discusión. Si es publicada y discutida por otros, en terrenos lógicos y posiblemente con base en nuevos experimentos emprendidos para probarla, la teoría puede ser rechazada si falla la prueba. Sólo después de estos esfuerzos intelectuales e interacciones con el mundo 1 puede alguien descubrir algunas aplicaciones (electrónica) que cambien el mundo"70. Si la ciencia es un proceso de selección la interacción debe tener lugar también. Es decir, las teorías tienen su propio ambiente. Puede decirse, en la lógica de Hull, que hay un ecosistema en el que las teorías interactúan con otras, esto es parecido al mundo 3 de Popper. En este sentido, los científicos no son sólo replicadores, es decir reproductores de las ideas, son también interactores pues las ideas sufren cambios al pasar de uno a otro científico; los científicos no son simples vehículos que transmiten ideas inmodificables. En fin, parece claro que las diferencias entre los niveles social y conceptual de la evolución del conocimiento son demasiado importantes como para dejarlas de lado.

(19) Popper, (1977), op. cit., p. 40

70) Ibid, p. 39 